\title{
Cadmium-Induced Behavioral Changes in Growing Rats
}

\author{
Key words : $\mathrm{Cd}^{2+}-$ Motor Activity-Conditioned Avoidance-Growing Rats-Be- \\ havior-Toxicity
}

Cadmium $\left(\mathrm{Cd}^{2+}\right)$ has been recognized as an environmental hazard since the incidence of the 'Itai-Itai' disease in Japan. ${ }^{1)}$ Exposure to $\mathrm{Cd}^{2+}$ in animals has been shown to cause neuropathological ${ }^{3)}$ and neurochemical changes. ${ }^{4)}$ But experimental studies assessing the behavioral effects of $\mathrm{Cd}^{2+}$ are scant and we undertook this preliminary investigation to assess the effects of $\mathrm{Cd}^{2+}$ on locomotor activity and learning performance in growing rats since young animals have been shown to be more susceptible to the neurotoxic effects of $\mathrm{Cd}^{{ }^{2+5} \text { ) }}$

Sixty growing male albino rats of the ITRC bred colony, weighing 150-160 g ( 2 months old), served as subjects. They were housed in stainless steel cages, in groups of ten and maintained on a 12:12 photoperiod (lights on 06.00-18.00 $\mathrm{hr})$ in a temperature controlled $\left(22 \pm 2.0^{\circ}\right)$ room. Hind Lever Laboratory chow and water were provided ad lib.

The animals were divided into two equal groups and the experimental group was administered $0.5 \mathrm{mg} \mathrm{Cd}{ }^{2+} / \mathrm{kg}$, i.p., as cadmium acetate (volume of injection $1 \mathrm{ml} / \mathrm{kg})$ daily for 21 days. The vehicle $(0.9 \% \mathrm{NaCl})$ injected rats served as controls. The animals were weighed weekly and the following behavioral and chemical parameters were measured at the end of the treatment priod.

The rats were placed individually in a photoactometer (Techno, India) and after $5 \mathrm{~min}$. acclimation period, the activity counts for $15 \mathrm{~min}$. were recorded. Twelve rats (in batches of 6 ) from each group were used.

The conditioned avoidance behavior was assessed in a pole climbing chamber (Techno, India). Each animal, after a $5 \mathrm{~min}$. habituation in the experimental chamber, was subjected to 50 trials. A trial consisted of the presentation of continuous $90 \mathrm{~dB} 1500 \mathrm{~Hz}$ tone conditioned stimulus (CS) for $10 \mathrm{sec}$. followed by the unconditioned stimulus (US), a $0.5 \mathrm{~mA}$ constant current scrambled foot shock for $10 \mathrm{sec}$. and a $40 \mathrm{sec}$. intertrial interval. The tone remained on when the shock was presented. The animals could avoid the shock by climbing the pole suspended from the middle of the roof and ending $5 \mathrm{~cm}$ from the grid floor. Responses were designated as follows: (a) conditioned avoidance response (CAR) when the animal climbed the pole in response to the CS, (b) Escape response (ER) when it climbed the pole during the foot shock, and (c) escape failure (EF) if it did not respond to the CS and US, when the shock was turned off and the next intertrial interval was started. The CAR, ER and EF responses as well as the intertrial responses, i.e., climbing the pole during the intertrial interval, were recorded. Twelve rats from each group (in batches of 6) were used 
for the assessment of the learning performance. The behavioral tests were conducted in a quiet, air-conditioned room $\left(22 \pm 2{ }^{\circ} \mathrm{C}\right)$ between 10.0 and $16.0 \mathrm{hr}$ by observers unaware of the treatment schedules and both the time and day of testing were counterbalanced within groups.

The animals ( 6 rats/group) were killed by decapitation on day 22 nd of treatment. Brain samples were wet ashed in nitric: perchloric acid (6:1) and cadmium residues were determined by Atomic absorption spectrophotometer (Perkin Elmer Model 5000).

Statistical evaluation of the data for the conditioned avoidance experiments, i.e., CAR, ER and EF, was done by a $3 \times 2$ Chi-square $\left(\mathrm{X}^{2}\right)$ test, $\left.{ }^{6}\right)$ using the frequency of the different responses. The data for body weight, motor activity, brain $\mathrm{Cd}^{2+}$ levels and intertrial response was analysed by the student's ' $t$ ' test. The accepted level of significance in either test was $\mathrm{p}<0.05$.

Fig. 1 shows the effect of $\mathrm{Cd}^{2+}$ exposure on the body weight growth pattern. The $\mathrm{Cd}^{2+}$ treated rats showed a significant growth retardation over the experimental period.

The SMA was significantly depressed in the $\mathrm{Cd}^{2+}$ treated rats compared to the controls and the $15 \mathrm{~min}$. counts in the control and experimental groups were

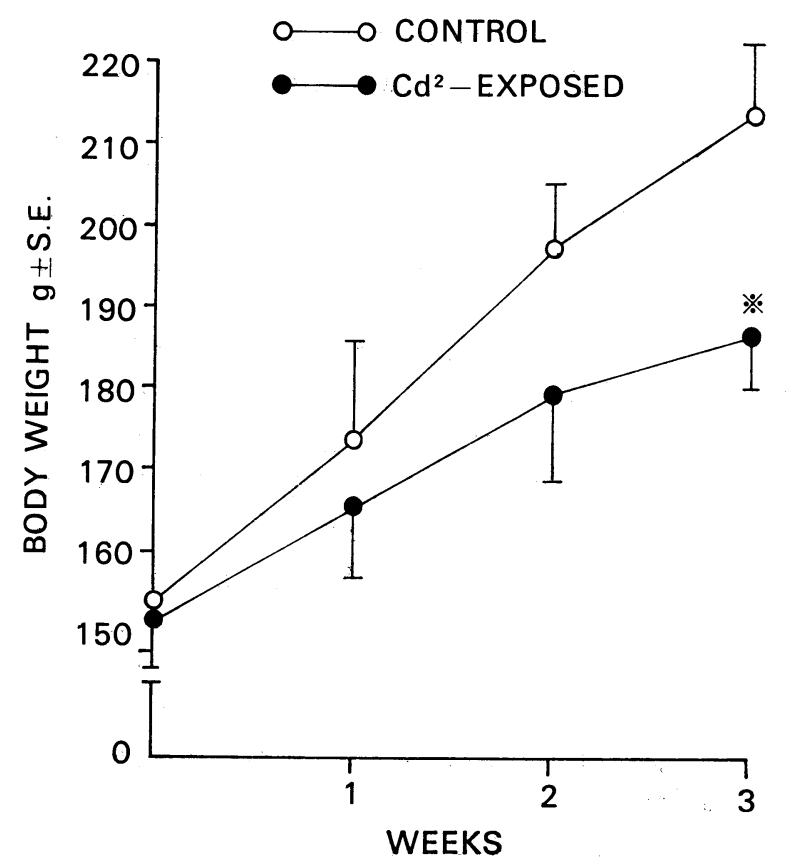

Fig. 1. Body weight growth pattern of control and $\mathbf{C d}^{2+}$ exposed rats over the experimental period.

Each point represents the mean weight \pm S.E. of 10 rats.

$* \mathrm{p}<0.05$ 


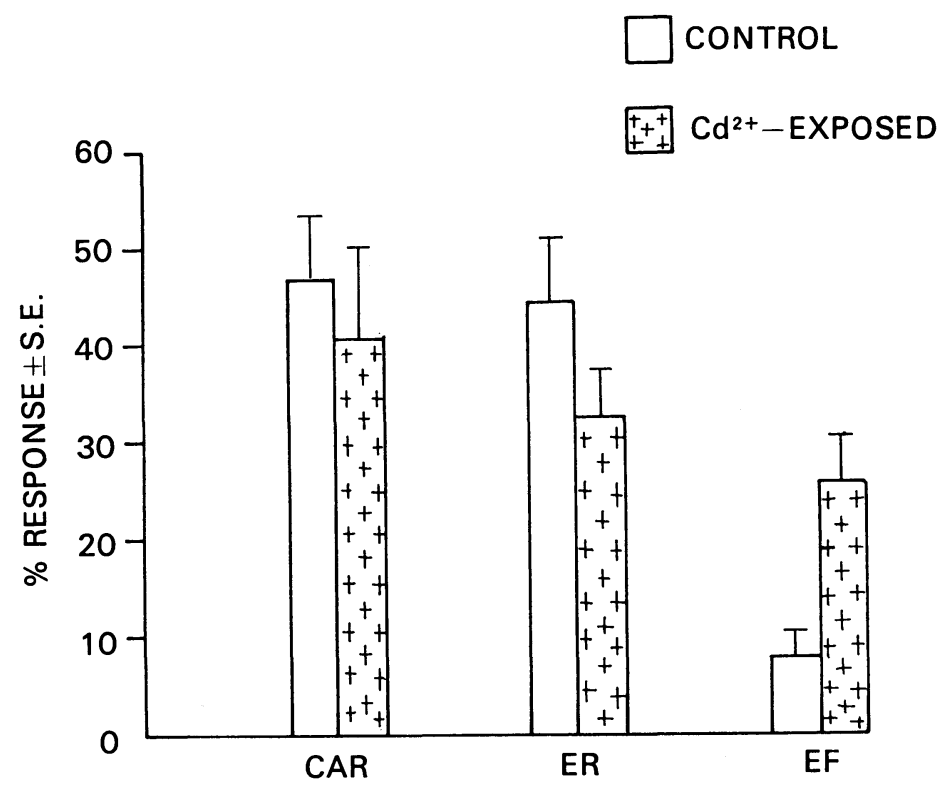

Fig. 2. Effect of $\mathrm{Cd}^{2+}-$ exposure on the CAR, ER and EF responses as tested in the pole climbing chamber, at the end of the treatment period.

Each bar represents the mean percentage response \pm S.E. of 12 rats.

$588 \pm 33$ and $297 \pm 21$ (Mean \pm S.E.; $\mathrm{p}<0.001$ ), respectively.

The effect of $\mathrm{Cd}^{2+}$ exposure on CAR, ER and EF is shown in Fig. 2. The $\mathrm{X}^{2}$ test revealed that the results of the conditioned avoidance experiment were not independent of the treatment $\left(\mathrm{X}^{2}{ }_{(2)}=6.87, \mathrm{p}<0.05\right)$. As evident from Fig. 2, the considerably higher incidence of $\mathrm{EF}$ in the $\mathrm{Cd}^{2+}$ treated group seems to have contributed to the significant value of $\mathrm{X}^{2}$. The intertrial response means did not differ significantly as tested by student's ' $\mathrm{t}$ ' test (Control $=16 \pm 3, \mathrm{Cd}^{2+}$-treated $=14 \pm 4)$.

The brain $\mathrm{Cd}^{2+}$ level in the control group was $0.275 \pm 0.25$ whereas in the experimental group it was $0.386 \pm 0.028 \mu \mathrm{g} / \mathrm{g}$ fresh weight $(\mathrm{p}<0.02)$.

The results indicate that the $\mathrm{Cd}^{2+}$ exposure, in growing rats resulted in a significant growth retardation, decrease in SMA and a marked increase in the escape failure response. The brain $\mathrm{Cd}^{2+}$ level registered a low residue accumulation.

The reduction in body weight due to $\mathrm{Cd}^{2+}$ exposure is well documented. ${ }^{7,8)}$ The few reports on the effects of $\mathrm{Cd}^{2+}$ on the locomotor activity in rats, seem to be variable and direct comparison of these results is made difficult by the differences in the age, dose and route of administration. But on the whole, the picture emerges that at low dose levels, $\mathrm{Cd}^{2+}$ exposure results in hyperactivity9) whereas at higher dose levels, decreases in locomotor activity, ${ }^{9)}$ open field ex- 
ploratory activity and rearing response ${ }^{10}$ ) have been observed. It is likely that the effect of $\mathrm{Cd}^{2+}$ on SMA varies with the age of the animals as well as the dose and route of administration.

The exact nature of the mechanism responsible for the increase in the EF response is not clear. Experimental studies indicate that $\mathrm{Cd}^{2+}$-exposure causes alterations in the sensory perception, ${ }^{3,11)}$ neuromuscular blockade, ${ }^{2)}$ deficit motor performance ${ }^{10)}$ and increased reactivity to physical stressors. ${ }^{3)}$ These alterations, which are incompatible with goal oriented responding, may be responsible for the increase in the escape failure response.

Thus, our results show that, in spite of the low accumulation of $\mathrm{Cd}^{2+}$ in the brain it does appear to cause certain behavioral dysfunctions in growing rats, even after a short term exposure.

\section{REFERENCES}

1) Kazantzis, G. (1973). Metal contaminants in the environment. Practitioner, 210, 482.

2) Foreshaw, P. J. (1977). The inhibitory effect of cadmium on neuromuscular transmission in the rat. Eur. J. Pharmac. 42, 371.

3) Gabbiani, G., Gregory, A. and Baic, D. (1967). Cadmium induced selected lesions of sensory ganglia. J. Neuropath. Exp. Neurol. 26, 498.

4) Singhal, R. L., Merali, Z. and Hridina, P. D. (1976). Aspects of the biochemical toxicology of cadmium. Fedn. Proc. 35, 75.

5) Wong, K. L. and Klaassen, C. D. (1982). Neurotoxic effects of cadmium in young rats. Toxicol. Appl. Pharmacol. 63, 330.

6) Siegel, S. (1956). Nonparametric statistics for the behavioral sciences, p. 104, McGrawHill, New York.

7) Itokawa, Y., Abe, T. Tabei, R. and Tanaka, S. (1974). Renal and Skeletal lesions in experimental cadmium poisoning. Arch. Environ. Hlth. 28, 149.

8) Prigge, E. (1978). Early sign of oral and inhalative cadmium uptake in rats. Arch. Toxicol. 40, 231.

9) Smith, M. J., Pihl, R. O., and Garber, B. (1982). Postnatal cadmium exposure and long-term behavioral changes in the rat. Neurobehav. Toxicol. Teratol. 4, 283.

10) Pfister, W. R. L., Pellegrino, L. J. and Yim, G. K. W. (1978). Behavioral aspects of cadmium toxicity in rats. Fedn. Proc. 37, 395.

11) Prodan, L. (1932). Cadmium poisoning: II. Experimental cadmium poisoning. J. Ind. Hyg. 14, 174.

Metal Toxicity Project

Industrial Toxicology Research Centre

P.O. Box No. 80, Lucknow-226 001, India
Satya V. CHANDRA

Ramesh C. MURTHY

and Mohd. M. ALI

(Received July 11, 1984 and in revised form January 11, 1985) 